\title{
Discussion to Dr Scher's paper (read by Dr Shrosbree) and the papers of Mr I. M. Nuseibeh and R. G. Burr

\author{
Chairman: Mr. E. R. GRIFFITHS
}

Professor A. Rossier (U.S.A.). I have just one question to Mr Burr. You showed the saturation curve for the brushite, did you do the same for the struvite? And for Dr Shrosbree: You mentioned in the upper motor neurone lesion that one of the characteristics in your presentation was a small bladder. I would object to this. You may have upper motor neurone bladders which are atonic and which show a very large capacity especially in tetraplegic in some types of tetraplegics, although their bladder has never been distended initially, so I think just the appearance or even the recording during the cystometrogram is not safety proof 100 per cent.

Dr SHrosbree (South Africa). I agree. One must take all points into consideration, not just a single point as regards the assessment of the bladder.

MR R. G. BURR (G.B.). The struvite is identical with magnesium ammonium phosphate. I apologise for not mentioning this synonymous term which we measured in all our patients. In the patients we studied the level of saturation of struvite was less than that of brushites.

MR GRIfFITHS. Any further questions? I'd like to make one comment. I think it was Mr Burr said that despite high concentrations you aren't likely to get calculi in non-paraplegic people. I think this depends on where you are. I seem to remember doing at least two or three bladder or kidney calculi a week in Arabia and you drink a pint of water a day because you haven't got any more than that, you sweat profusely in a temperature of $100^{\circ}$ and you have a vegetable and rice diet and these are all three that are combined to make a very high incidence of calculi in non-paraplegic people. I wonder if people from other hot countries would agree with this. It is very common. I would say every operating list would have at least one or two calculi on it.

Dr Fellows (G. B.). I'd like to ask Dr Burr a question. He has measured 24-hour urine volumes and the concentrations in them. I'd like to ask if he has studied any patient during the 24 -hour period. Is there a diurnal variation in the concentration of salts in the urine. He also stated that in most patients it is impossible to bring down the calcium phosphate product. Merely by drinking more alone would it be possible to phase the drinking over a particular part of the 24 hours say late in the evening and have the desired effect.

MR BURR (G.B.). We haven't studied small samples from our patients. I should have stressed the way we've been thinking about it was to allow a margin between the volume indicated on the nomogram to allow a substantial margin of additional water. Certainly there is a diurnal variation and it is a very interesting suggestion that the excretion of calcium and phosphate is greater during the day. One would think that by drinking more at that time it would certainly do this. One is always worried about the night time when people tend to go to bed and not drink at night and the urine becomes very concentrated. This is usually the more difficult problem.

Mr NuSEIBEH (G.B.). It is very difficult to regulate patients as a sort of machine to drink a glass of water every hour or two or what have you. The whole idea is how much output during and after 24 hours which keeps washing out the renal system and this is what we took into consideration to take the mean value of the whole 24 hours. I hope this will explain it.

DR Chawla (G.B.). Obviously when there is a catheter present there is more tendency that the stone formation is more and what happened in both cases. Have they studied any cases and so found what their calcium and phosphate level was with catheters in situ, because there is a precipitation when the catheters are there.

Mr NuSEIBEH. No, we did not take this into consideration, we just took the urinary output; but we do accept that the catheter acts as a foreign body as mentioned by $\mathrm{Mr}$ Burr and it helps in the precipitation of phosphates. 